This item was submitted to Loughborough's Research Repository by the author.

Items in Figshare are protected by copyright, with all rights reserved, unless otherwise indicated.

\title{
Preparation of liposomes: a novel application of microengineered membranes-from laboratory scale to large scale
}

\section{PLEASE CITE THE PUBLISHED VERSION}

http://dx.doi.org/10.1016/j.colsurfb.2013.07.066

\section{PUBLISHER}

(C) Elsevier B.V.

\section{VERSION}

AM (Accepted Manuscript)

\section{LICENCE}

CC BY-NC-ND 4.0

\section{REPOSITORY RECORD}

Laouini, Abdallah, Catherine Charcosset, Hatem Fessi, R.G. Holdich, and Goran T. Vladisavljevic. 2014. "Preparation of Liposomes: A Novel Application of Microengineered Membranes-from Laboratory Scale to Large Scale". figshare. https://hdl.handle.net/2134/14442. 
This item was submitted to Loughborough's Institutional Repository (https://dspace.lboro.ac.uk/) by the author and is made available under the following Creative Commons Licence conditions.

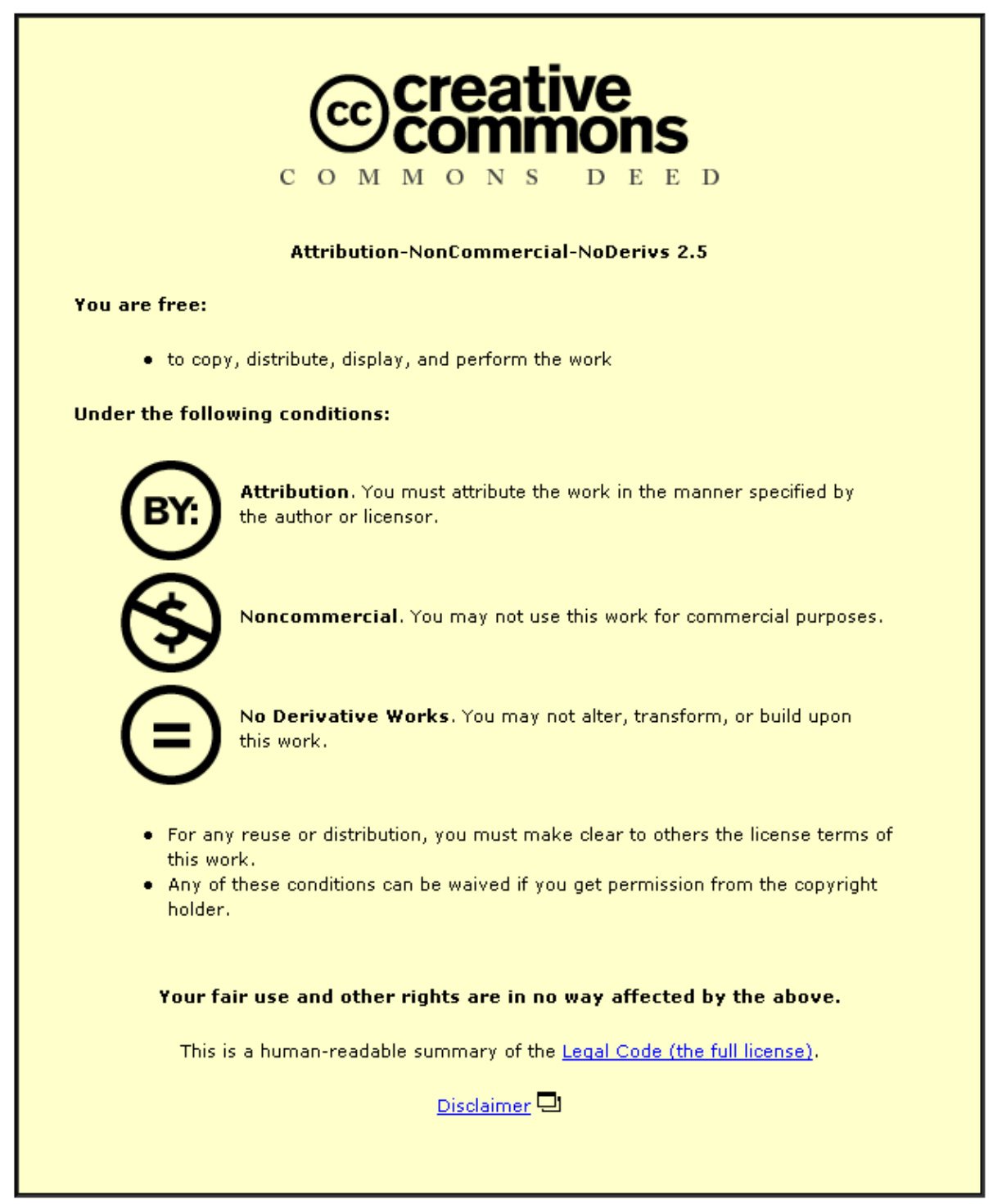

For the full text of this licence, please go to: http://creativecommons.org/licenses/by-nc-nd/2.5/ 


\section{Original research}

\section{Preparation of Liposomes: A Novel Application of Microengineered Membranes - From Laboratory Scale to Large Scale}
A. Laouini ${ }^{1,2}, \mathrm{C}$.
C. Charcosset ${ }^{2}$, H. Fessi ${ }^{2}$, R.
R.G. Holdich ${ }^{1}, \mathrm{G} . T$.
G.T. Vladisavljević ${ }^{*}$

1: Loughborough University, Department of Chemical Engineering, Loughborough, Leicestershire, LE11 3TU, United Kingdom

2: Université Claude Bernard Lyon 1, Laboratoire d'Automatique et de Génie des Procédés (LAGEP), UMR-CNRS 5007, CPE Lyon, Bat 308 G, 43 Boulevard du 11 Novembre 1918, F-69622 Villeurbanne Cedex, France.

*: To whom correspondence should be addressed: g.vladisavljevic@lboro.ac.uk

Tel: + 44 (0) 1509 222518; Fax: + 44 (0) 1509223923 


\section{Abstract}

A novel ethanol injection method using microengineered nickel membrane was employed to produce POPC (1-palmitoyl-2-oleoyl-sn-glycero-3-phosphocholine) and Lipoid $^{\circledR}$ E80 liposomes at different production scales. A stirred cell device was used to produce $73 \mathrm{ml}$ of the liposomal suspension and the product volume was then increased by a factor of 8 at the same transmembrane flux $\left(140 \mathrm{I} \mathrm{m}^{-2} \mathrm{~h}^{-1}\right)$, volume ratio of the aqueous to organic phase (4.5) and peak shear stress on the membrane surface $(2.7 \mathrm{~Pa})$. Two different strategies for shear control on the membrane surface have been used in the scaled-up versions of the process: a cross flow recirculation of the aqueous phase across the membrane surface and low frequency oscillation of the membrane surface $(\sim 40 \mathrm{~Hz})$ in a direction normal to the flow of the injected organic phase. Using the same membrane with a pore size of $5 \mu \mathrm{m}$ and pore spacing of $200 \mu \mathrm{m}$ in all devices, the size of the POPC liposomes produced in all three membrane systems was highly consistent $(80-86 \mathrm{~nm})$ and the coefficient of variation ranged between 26 and $36 \%$. The smallest and most uniform liposomal nanoparticles were produced in a novel oscillating membrane system. The mean vesicle size increased with increasing the pore size of the membrane and the injection time. An increase in the vesicle size over time was caused by deposition of newly formed phospholipid fragments onto the surface of the vesicles already formed in the suspension and this increase was most pronounced for the cross flow system, due to long recirculation time. The final vesicle size in all membrane systems was suitable for their use as drug carriers in pharmaceutical formulations.

\section{Key words:}

Liposomes - Ethanol injection method - Process scale-up - Stirred cell - Cross flow - Oscillating membrane 


\section{Preparation of Liposomes: A Novel Application of Microengineered Membranes - From Laboratory Scale to Large Scale}

\section{Introduction}

Liposomes are versatile drug carrier systems that can be tailor-made to accommodate a large variety of drugs for a wide range of therapies. Both lipophilic and hydrophilic drugs can be incorporated in liposomes, within the phospholipid bilayer and in the aqueous core, respectively [1]. The behaviour of liposomes in vivo and in vitro can be controlled by selecting the proper characteristics such as vesicle size, number of bilayers, bilayer fluidity, charge and hydrophilicity of the external surface, and the type of targeting molecules attached to the bilayer surface [2]. The applications of lipid vesicles are determined by their properties, which depend on molecular and physicochemical parameters as well as on the method of liposome preparation [3]. Therefore, a well-characterized methodology for liposome manufacture with validated operating procedures is the main requirement for producing liposomal populations with acceptable reproducibility and appropriate for the intended use.

Liposomal preparations can be manufactured using a wide variety of methods such as thin film hydration, reversed-phase evaporation, detergent dialysis, and solvent injection [4]. The major challenge in liposome production is still large scale production. Indeed, most of the described preparation techniques are not suitable for scaling up from the laboratory level to the industrial production, due to their complexity and a low reproducibility and predictability of the preparations obtained. A lack of predictability of product quality may be attributed to empirical methods traditionally employed for the design of lipid-based delivery systems [5]. Thus, there is a strong need to improve traditional manufacturing techniques, leaving behind those poorly characterizable methods, based on small batch sizes.

The ethanol injection method can be used for liposome production at large scale. In this process, an ethanolic solution of the lipid mixture is dispersed into an aqueous solution through fast injection. From the manufacturing point of view, this technique does fulfil the need for a rapid, simple, easily scalable and safe preparation technique. Also, this method does not promote degradation or oxidative alterations either in the lipid mixture or in active agents to be encapsulated [6].

Membrane dispersion, which is considered as an improvement of the ethanol injection technique, is a new method of producing liposomes of predetermined size. It involves mixing of two miscible liquids (the organic and aqueous phase) by injecting the organic phase through a microporous membrane into the aqueous phase. It is similar to membrane emulsification [7, 8], which involves the injection of one liquid (the dispersed phase) into another immiscible liquid (the continuous phase) through a microporous membrane $[9,10]$. Micro-engineered membranes, 
which have a perfect hexagonal array of uniform pores, allow a much more uniform and controllable injection of lipid-containing organic phase into an aqueous phase. Thus, their use enables a better control over diffusive mixing at the liquid/membrane interface where the lipids self-assemble into vesicles. This may provide fine control of liposome size distribution and make easier the extrapolation of the results for an industrial large scale production. The shear stress at the membrane surface can be controlled by [11]: (i) stirring the continuous phase using a paddle stirrer (Figure 1a); (ii) cross flow of the continuous phase along the membrane surface (Figure 1b); (iii) vibrating (oscillating) the membrane in the continuous phase (Figure 1c).

\section{Figure 1.}

Recent studies [10,12] were focused on the fabrication of liposomes using Shirasu Porous Glass (SPG) membrane. It was found that the vesicle size decreased with a decrease in the transmembrane flux and phospholipid concentration in the organic phase and with an increase in the aqueous to organic phase ratio and the shear stress on the membrane surface. Despite all the information provided in the literature regarding the effect of different operating and process conditions on vesicle characteristics [13-15], there is a lack of information regarding scale-up of liposomes production.

The aim of this study was to evaluate the scale-up of liposome production by a factor of 8 and beyond using novel ethanol injection method with microengineered membrane. For a small-scale production, a laboratory stirred cell was used, composed of a rotating stirrer above a flat disc membrane. For large scale production, two different methods were used: (a) recirculation of the continuous phase in cross flow along the membrane surface, and (b) oscillation of the membrane surface in a direction normal to the flow of the injected phase.

\section{Materials and methods}

\subsection{Reagents}

Phospholipids used in this study were POPC (1-palmitoyl-2-oleoyl-sn-glycero-3phosphocholine) and Lipoid ${ }^{\circledR}$ E80 (obtained from egg yolk lecithin and containing $82 \%$ of phosphatidyl-choline and $9 \%$ of phosphatidyl-ethanolamine), both purchased from Lipoïd GmbH (Ludwigshafen, Germany). Cholesterol and phosphotungstic acid were supplied by Sigma-Aldrich Chemicals (Saint Quentin Fallavier, France). $95 \%$ analytical-grade ethanol was supplied by Fisher Scientific (United Kingdom) and used as such, without further purification. Ultra-pure water was obtained from a Millipore Synergy ${ }^{\circledR}$ system (Ultrapure Water System, Millipore).

\subsection{Membranes}

The membranes used were nickel microengineered membranes containing uniform cylindrical pores arranged in a hexagonal array with a diameter of 5 or $20 \mu \mathrm{m}$ and pore spacing of $200 \mu \mathrm{m}$. The membranes were fabricated by the UV-LIGA process, 
which involves galvanic deposition of nickel onto a template formed by photolithography [16]. All membranes were supplied by Micropore Technologies Ltd. (Hatton, Derbyshire, United Kingdom).

\subsection{Experimental equipment}

Schematic illustration of the equipment used is presented in Figure 2.

\section{Figure 2.}

Stirred cell device. A Dispersion Cell was supplied by Micropore Technologies Ltd. (Hatton, Derbyshire, UK). This device uses a $24 \mathrm{~V}$ DC motor (INSTEK model PR 3060 ) to drive a paddle-blade stirrer at an adjustable speed controlled by the applied voltage. An effective diameter of the membrane fitted at the bottom of the cell was $3.3 \mathrm{~cm}$ and a membrane area was $8.55 \mathrm{~cm}^{2}$. The organic phase was injected through the membrane using a peristaltic pump (Watson Marlow 101U, Cornwall, UK).

Cross flow system. Cross flow module (Micropore Technologies Ltd) was composed of 4 separate disk membranes, each with a diameter of $7 \mathrm{~mm}$, so the total membrane surface area was $1.54 \mathrm{~cm}^{2}$. The cross flow channel was $20 \mathrm{~mm}$ wide and $1 \mathrm{~mm}$ high. A syringe pump (Havard Appartus 11 Plus) was used to inject the organic phase through the membranes and a peristaltic pump (Watson Matlow 603s, Cornwall, UK) was used to recycle the aqueous phase between the module and an aqueous phase tank.

Oscillating membrane system. This system was also supplied by Micropore Technologies Ltd. The membrane was composed of 2 foils rolled in the form of a ring with a diameter of $30 \mathrm{~mm}$ and a length of $20 \mathrm{~mm}$. The membrane had an area of $34.1 \mathrm{~cm}^{2}$ and was attached to the injection manifold to which an accelerometer was fixed. The accelerometer (PCB Piezotronics model M352C65) was connected to a National Instruments Analogue to Digital Converter (N1 Edaq-9172) which was interfaced to a LabView executable program running on a computer. The information provided by the program from the accelerometer was the frequency and the amplitude of the oscillations, the amplitude being determined by the direction of the travel and the frequency was deduced from the acceleration measurement. The oscillation signal was provided by an audio generator (Rapid Electronics), which fed a power amplifier driving the electro-mechanical oscillator on which the inlet manifold was mounted. The injection manifold had internal drillings to allow the passage of the organic phase by a syringe pump (Harvard Apparatus 11 Plus).

\subsection{Experimental procedure and shear stress calculation}

The organic phase was composed of $20 \mathrm{mg} \mathrm{ml}^{-1}$ of phospholipids and $5 \mathrm{mg} \mathrm{ml}^{-1}$ of cholesterol (used as a stabilizer) dissolved in ethanol.

Stirred cell system. The cell was filled with $60 \mathrm{ml}$ of ultrapure water and $13 \mathrm{ml}$ of the organic phase was injected through the membrane at $2 \mathrm{ml} \mathrm{min}^{-1}$ to achieve a 
final volume ratio of the aqueous to organic phase of 4.5. The organic phase flux, J, was given by:

$J=Q_{0} / A$

where $Q_{0}$ is the volume flow rate of the organic phase and $A$ is the membrane area. The organic phase flux was $140 \mathrm{I} \mathrm{m}^{-2} \mathrm{~h}^{-1}$, calculated from Eq. (1), and the stirrer speed was $600 \mathrm{rpm}$. Previous studies in Dispersion Cell $[17,18]$ have shown that a shear stress is not uniformly distributed over the membrane surface, but varies with the radial distance $r$, according to the equations [19]:

$\begin{array}{ll}\text { For } r<r_{\text {trans }} & \tau=0.825 \eta_{a q} \omega r \frac{1}{\delta} \\ \text { For } r>r_{\text {trans }} & \tau=0.825 \eta_{a q} \omega r_{\text {trans }}\left(r_{\text {trans }} / r\right)^{0.6} \frac{1}{\delta}\end{array}$

where $r_{\text {trans }}$ is the transitional radius, i.e. the radial distance from the center of the membrane at which the shear stress is greatest:

$r_{\text {trans }}=1.23 \frac{D}{2}\left(0.57+0.35 \frac{D}{T}\right)\left(\frac{b}{T}\right)^{0.036} n_{b}^{0.116} \mathrm{Re} /(1000+1.43 \mathrm{Re})$

where $D$ is the stirrer diameter, $T$ is the internal diameter of the stirred cell, $b$ is the blade height, and $n_{b}$ is the number of blades (Figure 2a). The Reynolds number, Re, is given by:

$\mathrm{Re}=\omega \rho_{a q} D^{2} /\left(2 \pi \eta_{a q}\right)$

where $\rho_{\mathrm{aq}}$ and $\eta_{\mathrm{aq}}$ are the density and viscosity of the aqueous phase, respectively, and $\omega$ is the angular velocity of the stirrer. The boundary layer thickness, $\delta$, is given by the Landau-Lifshitz equation [17]:

$\delta=\sqrt{\eta_{a q} /\left(\rho_{a q} \omega\right)}$

Since the shear stress at the membrane surface is not constant, it can be argued that the appropriate value that should be used in comparative investigations is either the average or maximum shear. Because the shear stress at $r=r_{\text {trans }}$ is the highest, the pressure above the membrane surface at $r=r_{\text {trans }}$ has a minimum value, leading to the maximum transmembrane pressure and thus the maximum flux through the membrane. Since the membrane is most productive near the transitional radius, the shear stress at $r=r_{\text {trans }}$ (maximum shear stress) will be used as a representative $\tau$ value in stirred cell experiments. Using Equation (2) or (3) and (6):

$\tau_{\max }=\frac{0.825 \eta_{a q} \omega r_{\text {trans }}}{\sqrt{\eta_{a q} /\left(\rho_{a q} \omega\right)}}$

In this study, the maximum shear stress was $4.7 \mathrm{~Pa}$ and the transitional radius was $1.1 \mathrm{~cm}$. A scale-up of stirred cell membrane systems is complicated, because the shear stress on the membrane surface is a complex function of the system geometry and the shear is non-uniformly distributed over the membrane surface (Figure 1a).

Cross flow system. $480 \mathrm{ml}$ of the aqueous phase was pumped through the crossflow channel and overall $107 \mathrm{ml}$ of the organic phase was injected through the 
membrane at $36 \mathrm{ml} \mathrm{min}{ }^{-1}\left(140 \mathrm{I} \mathrm{m}^{-2} \mathrm{~h}^{-1}\right)$ to achieve an aqueous to organic phase volume ratio in the final preparation of 4.5 . The shear stress on the membrane surface generated by cross flow in rectangular channel geometry is given by:

$$
\tau=3 Q_{a q} \eta_{a q} /\left(2 h^{2} W\right)
$$

where $Q_{a q}$ is the aqueous phase flow rate, and $h$ and $W$ are the height and width of the channel, respectively. In order to keep the same shear stress on the membrane

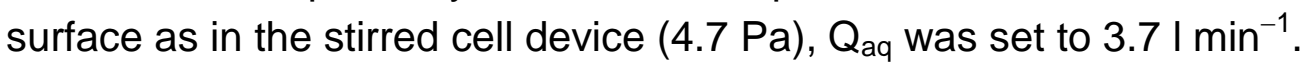

Oscillating membrane system. A ring membrane was immersed into a beaker containing $480 \mathrm{ml}$ of the aqueous phase. The aqueous phase was then sucked into the membrane and injection manifold using a syringe in order to ensure that no air bubbles were trapped within the organic phase. When air was completely removed, the injection tube was attached to the syringe pump. Then, overall $107 \mathrm{ml}$ of the organic phase was injected through the membrane at $8 \mathrm{ml} \mathrm{min}^{-1}\left(140 \mathrm{I} \mathrm{m}^{-2} \mathrm{~h}^{-1}\right)$ to achieve a final aqueous to organic phase volume ratio of 4.5. Oscillations did not start until the organic phase emerged on the membrane surface in order to prevent pre-mixing within the membrane. In a stirred cell or cross flow system, the shear stress does not vary over time at any location on the membrane surface. For oscillating membrane system, the shear stress on the membrane surface is a sinusoidal function of time (Figure 1c) and the maximum shear is given by:

$$
\tau_{\max }=(2 \pi)^{3 / 2}\left(\mu_{a q} \rho_{a q}\right)^{1 / 2} a f^{3 / 2}
$$

where $a$ and $f$ is the amplitude and frequency of the membrane oscillations. Eq. (9) suggests that the same $\tau_{\max }$ value can be achieved using many different sets of frequency and amplitude values. In membrane emulsification, the mean droplet size was found to be a function of the maximum shear stress only and not the frequency or amplitude used to achieve it [20]. In this study, the frequency and amplitude were adjusted to $40 \mathrm{~Hz}$ and $1.2 \mathrm{~mm}$, respectively, to obtain the maximum shear stress on the membrane surface which is consistent with the cross flow and stirred system (4.7 $\mathrm{Pa}$ ). Equation (9) implies that the oscillating membrane system is easy to scale up, because the surface shear does not depend on the membrane geometry or the geometry of the vessel, or channel, in which the membrane was fitted. A summary of the experimental conditions used in different systems is presented in Table 1.

\section{Table 1.}

In all systems, formation of vesicles occurred as soon as the organic phase was brought into contact with the aqueous phase. The liposomal suspension was collected and remaining ethanol was removed by evaporation under reduced pressure (Buchi, Flawil, Switzerland). After each experiment, the membrane was washed by sonication in ethanol for 1 hour, followed by soaking in a siloxane-based wetting agent for $30 \mathrm{~min}$ in order to increase the hydrophilicity of the surface.

\subsection{Liposomes characterization}


Size analysis. The particle size distribution was measured by differential centrifugal sedimentation using a CPS disc centrifuge, model DC 24000 (CPS instruments, Florida, USA). A light beam near the outside edge of the rotating disc passed through the centrifuge at some distance below the surface of the liquid phase and measured the concentration of particles as they settled. The time required for particles to reach the detecting beam depends upon the speed and geometry of the centrifuge, the difference in density between the particles and the surrounding liquid, and the size of the particles. Thus, when operating conditions were stable, sedimentation velocity increased with the particle diameter, so that the time needed to reach the detector beam was used to calculate the size of the particles [21, 22]. A sucrose gradient (from $18 \%$ to $26 \%$ ) was built and the sample was diluted in a sucrose solution (30\%) before being injected. Prior to the analysis, the instrument was calibrated using an aqueous suspension of polybutadiene particles of a known size distribution and a mean size of $402 \mathrm{~nm}$. The mean particle size of liposomes was expressed as the number-average mean diameter, $d_{a v}$ and the polydispersity was expressed as the coefficient of variation, $C V=\left(\sigma / \mathrm{d}_{\mathrm{av}}\right) \times 100$, where $\sigma$ is the standard deviation of particle diameters in a suspension. The smaller CV values indicate the narrower size distribution [23, 24]. All $d_{a v}$ and CV values will be expressed as the mean \pm standard deviation (S.D.).

Microscopic observation. The morphology of the liposomes was observed by transmission electron microscopy (TEM) using a CM 120 microscope (Philips, Eindhoven, Netherlands) operating at an accelerating voltage of $80 \mathrm{KV}$. A drop of the liposome dispersion was placed on a holey copper grid. A thin film of the liposome dispersion was obtained by removing excess solution using a filter paper. Negative staining with $2 \%(\mathrm{w} / \mathrm{w})$ phosphotungstic acid was directly performed on the deposit for $1 \mathrm{~min}$. The excess of phosphotungstic solution was removed with a filter paper after which the stained samples were transferred to the TEM for imaging.

\section{Results and discussion}

\subsection{Effect of the phospholipid type}

The characteristics of Lipoid E 80 and POPC vesicles obtained in stirred cell and cross-flow systems using membranes with two different pore sizes are compared in Table 2. The POPC liposomes prepared using the pore size of $5 \mu \mathrm{m}$ were smaller and more uniform than Lipoid E80 liposomes prepared using the same pore size and the difference was more significant for cross-flow system, due to longer fabrication times. It should be noted that both Lipoid E 80 and POPC allow the formation of liposomes with an acceptable size for their use as drug carriers in pharmaceutical formulations. Therefore, both phospholipids can be used for large scale production of liposomes in a cross-flow membrane system.

\section{Table 2.}

\subsection{Effect of the membrane pore size}


The effect of membrane pore size on the mean size of vesicles prepared in stirred cell and cross flow systems can be seen in Table 2. Clearly, the mean liposome size increased with increasing the pore size, and the effect was more pronounced for the cross-flow system, due to longer fabrication time. In the cross flow system, new phospholipid molecules supplied through the membrane by the organic phase were partly deposited on the existing liposomal particles that recirculate through the module, and partly form new phospholipid fragments in the aqueous phase. As a result, the liposomal particles formed in the cross flow system are larger than those formed in the stirred cell, where a secondary particle growth is less pronounced due to shorter injection time. The effect of the pore size on the vesicle size can also be seen in Figure 3. This figure shows that the mean vesicle size was between 50 and $100 \mu \mathrm{m}$ when $5-\mu \mathrm{m}$ membrane was used and 150 to $200 \mu \mathrm{m}$ when the membrane with a $20 \mu \mathrm{m}$ pore size was used. In membrane emulsification, the particle size was found to increase linearly with the pore size $[19,25,26]$. The results show that it is feasible to tune the size of liposomal particles by using microengineered membranes with different nominal pore sizes, but the effect is limited to a relatively narrow range of mean vesicle sizes.

\subsection{Variation of vesicle size with time during the scale up}

The samples of liposomal nanosuspension prepared in both the cross flow and oscillating system were taken at predetermined time intervals to investigate the variation of the vesicle size with time. The aqueous to organic phase ratio, $R$, during the fabrication process was inversely proportional to the process time, $\mathrm{t}$ :

$R=V_{a q} / V_{o}=V_{a q} /\left(Q_{o} t\right)$

where $V_{a q}$ is the initial volume of the aqueous phase in the system and $Q_{0}$ is the flow rate of the organic phase through the membrane, which was kept constant. Thus, higher $R$ values in the samples correspond to shorter processing times. As shown in Figure 3, the mean size and CV of vesicles in the liposomal suspension increased with time. It can be explained by assuming that the supersaturation in the aqueous phase was relieved by a combination of nucleation (formation of phospholipid fragments) and particle growth (precipitation of phospholipid fragments onto the surface of the vesicles already present in the suspension). Initially, formation of phospholipid fragments dominates over precipitation but subsequently, precipitation of material onto the existing vesicles becomes increasingly more important, leading to a gradual increase in the mean vesicle size. A polydispersity of vesicles in the suspension increased as a result of coexistence of small vesicles formed directly from phospholipid fragments and larger vesicles formed by precipitation onto the smaller vesicles. The large vesicles can also be produced at the higher phospholipid concentration in the organic phase, as suggested elsewhere [9, 10, 27, 28].

Figure 3. 
As shown in Figure 3, in the cross flow system, the mean vesicle size increased over time by $80 \%$ (from 58 to $108 \mathrm{~nm}$ ), whereas in the oscillating system the size variation over time was only by $8 \%$ (from 74 to $80 \mathrm{~nm}$ ). The model of vesicles formation proposed by Lasic [29] suggests that following their injection, phospholipids precipitate at the water/ethanol boundary and form bilayered phospholipid fragments. The energy needed to curve a flat bilayer fragment into a closed sphere was provided here through agitation of the aqueous phase, cross flow or membrane vibrations. When cross flow system was used, the recirculation of the formed vesicles in a closed loop facilitated their contact with the newly formed small vesicles and phospholipid fragments, which might result in the formation of bigger vesicles. A contact of phospholipid fragments with existing vesicles was pronounced by a narrow cross flow channel with a height of $1 \mathrm{~mm}$ and a long recirculation time.

The results in Figure 3 indicate that the vesicle size can be precisely controlled by monitoring the processing time, thereby controlling the amount of organic phase injected through the membrane. This finding is highly relevant since it can enable continuous production of liposomes with different mean particle sizes using a single pore size. It is important to note that both cross flow and oscillating membrane systems are scalable and the fabrication process developed in a small device can be carried out under the same shear conditions in a cross flow or oscillating system with a much larger membrane area. On the other hand, a stirred system is not scalable due to large spatial variations of the shear stress over the membrane surface (Fig. 1a) and a significant effect of the system geometry on the shear stress.

\subsection{Comparison of different fabrication methods}

Once optimized at small scale $\left(\mathrm{V}_{\mathrm{aq}}=60 \mathrm{ml}\right)$ in stirred cell, the fabrication of POPC liposomes was scaled up by a factor of $8\left(V_{\mathrm{aq}}=480 \mathrm{ml}\right)$ at constant $\mathrm{R}, \mathrm{J}$, and $\tau_{\max }$. The larger vesicle size and broader particle size distribution was obtained in the cross flow system, compared to that in the stirred cell (Table 3). The scale-up was done by maintaining constant $\mathrm{V}_{\mathrm{aq}} / \mathrm{V}_{\mathrm{o}}$ and $\mathrm{J}$ values and thus, the fabrication time, $\mathrm{t}$, should be proportional to $V_{a q} / A$. In the cross-flow system, the membrane area $A$ was 5.6 times smaller than that in the stirred cell and thus, for an eightfold increase in the aqueous phase volume, the process time in the cross-flow device should be 48 times longer than that in the stirred cell (Table 3). The recirculation of the liposomal suspension over a time period of $297 \mathrm{~min}$ led to an increase in the mean vesicle size since the newly formed bilayered fragments settle upon the already formed vesicles. This can explain why the mean vesicle size was increased from 81 to $86 \mathrm{~nm}$ when the cross flow system was used, instead of the stirred cell.

\section{Table 3}

The membrane oscillation was used as an alternative to cross flow in order to avoid the requirement for recirculation of the organic phase along the membrane surface. The shear stress on the membrane surface is a sinusoidal function of time (Fig. 1c), 
but at $40 \mathrm{~Hz}$, there were 80 peak shear events per second (one peak shear event every $12.5 \mathrm{~ms}$ ). The organic phase was split into more than 90 thousand streams within the membrane, before being mixed with an aqueous phase on the other side of the membrane. The average flow velocity of the organic phase in the pores was 7 $\mathrm{cm} \mathrm{s}^{-1}$ and the distance travelled by each stream between two peak shear events was less than $0.9 \mathrm{~mm}$. The mean vesicle size in the oscillating system was the same as that in the stirred cell and the CV improved from $29 \%$ to $26 \%$ (Table 3). Holdich et al. [20] attributed the better uniformity of the particles produced by the oscillating system to the fact that in such a system the shear stress is only applied at the membrane surface (where it is needed), while it is very low in the bulk of the aqueous phase. In addition, shear conditions on the membrane surface can be more finely adjusted by varying two parameters, the frequency and the amplitude of membrane oscillations. In the stirred cell, the shear can only be controlled by varying the stirrer speed. Zhu and Barrow [30] reported that the use of a vibrating membrane had a significant effect in reducing the size of the droplets generated in membrane emulsification.

The process capacity, defined as the volume of the liposomal suspension produced per unit time, was the maximum for the oscillating system (Table 3). The scale-up was done at constant flux and $\mathrm{V}_{\mathrm{aq}} / \mathrm{V}_{\mathrm{o}}$ and thus, the process capacity was proportional to $\mathrm{A} / \mathrm{V}_{\mathrm{aq}}$ and inversely proportional to the process time. The fabrication time in the oscillating system was about 23 times shorter than that in the cross-flow system resulting in the higher capacity of the oscillating system by a factor of 23 .

Table 4 summarises potential advantages and disadvantages of the various membrane systems used for liposomes preparation. An advantage of cross-flow and oscillating system is that the volume of the aqueous phase is decoupled from the membrane area. In a stirred cell, the aqueous phase volume is limited by the membrane area, because $\mathrm{D} / \mathrm{H}$ should be within certain limits to achieve a satisfactory mixing rate. Another advantage of cross-flow and oscillating membrane systems over batch stirred cells is that cross-flow and oscillating systems can be operated continuously or semi-continuously and a total membrane area in these systems can easily be increased by adding additional membrane elements and assemblies.

\section{Table 4.}

\subsection{TEM observation}

Liposomes prepared with different techniques were observed by Transmission Electron Microscopy (TEM) and TEM micrographs are given in Figure 4.

\section{Figure 4.}

As could be seen, liposomes were spherical with multilayered membrane structure specific to multilamellar vesicles. Their size estimated from TEM pictures ranged 
from 60 to $120 \mathrm{~nm}$ which is coherent with the values obtained using the CPS instrument.

\section{Conclusion}

Multilamellar phospholipid vesicles were produced by injection of ethanolic phase through a microengineered membrane into aqueous phase using different membrane devices and batch sizes. The process developed in a stirred cell device was scaled-up by a factor of 8 by maintaining the same transmembrane flux, peak shear stress on the membrane surface and aqueous to organic phase phase ratio. In the cross flow system, the vesicle size increased over time due to continual recirculation of the liposomal suspension. The oscillating membrane system, which avoids recirculation of the liposomes was fully capable of maintaining the size and polydispersity of the liposomal nanoparticles during scale-up. This technique can easily be further scaled up by providing a larger membrane area in the oscillating membrane assembly. By an appropriate manipulation of hydrodynamic conditions during the process scaling up, it is possible to obtain small liposomes with a narrow size distribution. These results show great potential of microengineered membranes with constant pore spacing to be used for design, rationalization and intensification of industrial production of liposomes.

\section{Acknowledgments}

Abdallah LAOUINI held a CMIRA Explora 2011 fellowship from "Région RhôneAlpes".

\section{Rhônftlpẹes}

The authors wish to thank Dr Marijana Dragosavac for fruitful discussions and useful advices. 


\section{References}

[1] Torchilin, V. P. Nat. Rev. Drug Discovery 2005, 4, 145-160.

[2] Liu, D.; Mori, A.; Huang, L. Biochim. Biophys. Acta 1992, 1104, 95-101.

[3] Stano, P.; Bufali, S.; Domazou, A.; Luisi, P. L. J. Liposome Res. 2005, 15, 29-47.

[4] Laouini, A.; Jaafar-Maalej, C.; Limayem-Blouza, I.; Gandoura-Sfar, S.; Charcosset, C.; Fessi, H. J Colloid Sci. Biotechnol. 2012, In press.

[5] Chen, M. Adv. Drug Delivery Rev. 2008, 60, 768-777.

[6] Meure, L. A.; Foster, N. R.; Dehghani, F. AAPS Pharm. Sci. Tech. 2008, 9, 798-809.

[7] Joscelyne, S. M.; Trägårdh, G. J. Membr. Sci. 2000, 169, 107-117.

[8] Charcosset, C.; Limayem, I.; Fessi, H. J. Chem. Technol. Biotechnol. 2004, 79, 209-218.

[9] Joscelyne, S. M.; Trägårdh, G. J. Membr. Sci. 2000, 169, 107-117.

[10] Laouini, A.; Jaafar-Maalej, C.; Sfar-Gandoura, S.; Charcosset, C.; Fessi, H. Int. J. Pharm. 2011. 415, 53-61.

[11] Vladisavljević, G. T.; Williams, R. A.; J. Colloid Interface Sci. 2006, 299, 396402.

[12] Laouini, A.; Jaafar-Maalej, C.; Sfar-Gandoura, S.; Charcosset, C.; Fessi, H. Prog. Colloid Polym. Sci. 2012, 139, 23-28.

[13] Pham, T. T.; Jaafar-Maalej, C.; Charcosset, C.; Fessi, H. Colloids Surf B. 2012, 94, 15-21.

[14] Justo, O. R.; Moraes, A. M. Chem. Eng. Res. Des. 2011, 89, 785-792.

[15] Wagner, A.; Karola, V.; Gunther, K.; Hermann, K. J. Liposome Res. 2002, 12, 259-270.

[16] Vladisavljević, G. T.; Kobayashi, I.; Nakajima, M. Microfluid. Nanofluid. 2012, 13, 151-178.

[17] Kosvintsev, S. R.; Gasparini, G.; Holdich, R. G.; Cumming, I. W.; Stillwell, M. T. Ind. Eng. Chem. Res. 2005, 44, 9323-9330.

[18] Stillwell, M. T.; Holdich, R. G.; Kosvintsev, S. R.; Gasparini, G.; Cumming, I. W. Ind. Eng. Chem. Res. 2007, 46, 965-972.

[19] Dragosavac, M. M.; Sovilj, M. N.; Kosvintsev, S. R.; Holdich, R. G.; Vladisavljević, G. T. J. Membr. Sci. 2008, 322, 178-188.

[20] Holdich, R. G.; Dragosavac, M. M.; Vladisavljević, G. T.; Kosintsev, S. R. Ind. Eng. Chem. Res. 2010, 49, 3810-3817.

[21] Fitzpatrick, S. T.; US patent number 5,786,898. 28 July 1998.

[22] Schucks, P. Biophys. J. 2000, 82, 1096-1111.

[23] Cheng, C.; Chu, L.; Xie, R. J. Colloid Interface Sci. 2006, 300, 375-382.

[24] Nazir, A.; Schroen, K.; Boom, M. J. Membr. Sci. 2010, 362, 1-11.

[25] Vladisavljević, G. T.; Schubert, H. J. Membr. Sci. 2003, 225, 15-23.

[26] Williams, R. A.; Peng, S. J.; Wheeler, D. A.; Morley, N. C.; Taylor, D.;

Whalley, M.; et al. Chem. Eng. Res. Des. 1998, 76 A 8, 902-910.

[27] Pradhan, P.; Guan, J.; Lu, D.; Wang, P. G.; Lee, L. G.; Lee, R. J. Anticancer Res. 2008, 28, 943-948.

[28] Kremer, J. M. H.; Vander Esker, M. W.; Pathmamanoharan, C.; Wiessema, P. H. Biochemistry 1977, 16, 3932-3935.

[29] Lasic D. D. Biochem. J. 1988, 256, 1-11.

[30] Zhu, J.; Barrow, D. J. Membr. Sci. 2005, 261,136-144. 
Table 1.

Experimental conditions used in different preparation methods. The aqueous to organic phase ratio, transmembrane flux and shear stress on the membrane surface were held constant to conduct experiments under comparable conditions.

\begin{tabular}{|c|c|c|c|}
\hline Preparation method & $\begin{array}{l}\text { Stirred cell } \\
\text { system }\end{array}$ & $\begin{array}{l}\text { Cross flow } \\
\text { system }\end{array}$ & $\begin{array}{c}\text { Oscillating } \\
\text { membrane system }\end{array}$ \\
\hline Aqueous phase volume (ml) & 60 & 480 & 480 \\
\hline Organic phase volume (ml) & 13 & 107 & 107 \\
\hline Final aqueous to organic phase volume ratio (-) & 4.5 & 4.5 & 4.5 \\
\hline Organic phase flow rate $\left(\mathrm{ml} \mathrm{min}{ }^{-1}\right)$ & 2 & 0.36 & 8 \\
\hline Membrane area $\left(\mathrm{cm}^{2}\right)$ & 8.55 & 1.54 & 34.1 \\
\hline Transmembrane flux $\left(\mathrm{I} \mathrm{m}^{-2} \mathrm{~h}^{-1}\right)$ & 140 & 140 & 140 \\
\hline Agitation speed (rpm) & 600 & N.A & N.A \\
\hline Aqueous phase flow rate $\left(I \mathrm{~min}^{-1}\right)$ & N.A & 3.7 & N.A \\
\hline Maximum shear stress on membrane surface $(\mathrm{Pa})$ & 4.7 & 4.7 & 4.7 \\
\hline
\end{tabular}




\section{Table 2.}

Influence of phospholipid type and membrane pore size on the mean vesicle size and $\mathrm{CV}$ in stirred cell and cross flow systems. The experimental conditions are specified in Table 1.

\begin{tabular}{ccccc}
\hline $\begin{array}{c}\text { Preparation } \\
\text { method }\end{array}$ & $\begin{array}{c}\text { Phospholipid } \\
\text { used }\end{array}$ & $\begin{array}{c}\text { Membrane pore } \\
\text { size }(\mu \mathrm{m})\end{array}$ & $\begin{array}{c}\text { Liposomes mean } \\
\text { size* }(\mathrm{nm})\end{array}$ & $\mathrm{CV}^{*}(\%)$ \\
\hline \multirow{3}{*}{$\begin{array}{c}\text { Stirred cell } \\
\text { system }\end{array}$} & Lipoid E 80 & 5 & $87 \pm 3$ & $32 \pm 1$ \\
\cline { 2 - 5 } & POPC & 5 & $91 \pm 3$ & $34 \pm 1$ \\
\hline & 5 & $81 \pm 3$ & $29 \pm 1$ \\
\multirow{2}{\text{Crossflow}}{\begin{tabular}{c} 
system \\
\cline { 2 - 5 }
\end{tabular}} & Lipoid E 80 & 20 & $105 \pm 3$ & $46 \pm 1$ \\
& POPC & 5 & $204 \pm 2$ & $45 \pm 2$ \\
\hline
\end{tabular}

*: Each value represents the mean \pm S.D. $(n=3)$ 
Table 3.

Comparison of different methods of liposome preparation. The phospholipid: POPC, final aqueous to organic phase volume ratio: 4.5 , membrane pore size: $5 \mu \mathrm{m}$. The other experimental conditions are specified in Table 1.

\begin{tabular}{cccccc}
\hline $\begin{array}{c}\text { Preparation } \\
\text { method }\end{array}$ & $\begin{array}{c}\text { Mean vesicle } \\
\text { size* }, \mathrm{nm}\end{array}$ & $\begin{array}{c}\mathrm{CV}^{*}, \\
\%\end{array}$ & $\begin{array}{c}\text { Suspension } \\
\text { volume, } \mathrm{ml}\end{array}$ & $\begin{array}{c}\text { Process } \\
\text { time, min }\end{array}$ & $\begin{array}{c}\text { Process } \\
\text { capacity, } \\
\mathrm{ml} \mathrm{min}^{-1}\end{array}$ \\
\hline Stirred cell & $81 \pm 3$ & $29 \pm 1$ & 73 & 6.5 & 11 \\
Cross flow & $86 \pm 2$ & $36 \pm 2$ & 587 & 297 & 2 \\
$\begin{array}{c}\text { Oscillating } \\
\text { system }\end{array}$ & $80 \pm 2$ & $26 \pm 1$ & 587 & 13 & 45 \\
\hline
\end{tabular}

${ }^{*}$ : Each value represents the mean \pm S.D. $(n=3)$ 
Table 4.

Comparison of different membrane systems used in this work for fabrication of liposomes.

\begin{tabular}{|c|c|c|}
\hline $\begin{array}{c}\text { Preparation } \\
\text { method }\end{array}$ & Potential advantages & Potential disadvantages \\
\hline Stirred cell system & $\begin{array}{l}\text { - Laboratory test system, easy to use in order to } \\
\text { study the effect of different experimental conditions } \\
\text { on the preparation characteristics. } \\
\text { - High injection rates of the dispersed phase through } \\
\text { the membrane. } \\
\text { - Suitable for low volumes of aqueous phase. }\end{array}$ & $\begin{array}{l}\text { - Suitable only for small scale production (the batch } \\
\text { volume was limited to } 120 \mathrm{ml} \text { ). } \\
\text { - } \quad \text { Suitable only for batch-wise operation. } \\
\text { - A non-uniform shear stress at the membrane surface, } \\
\text { which depends on the cell geometry. }\end{array}$ \\
\hline Cross flow system & $\begin{array}{l}\text { - } \quad \text { Constant shear stress at the membrane surface. } \\
\text { - } \quad \text { Modules widely available and easy to use. } \\
\text { - } \quad \text { Suitable for large scale production and continuous } \\
\text { or semi-continuous operation. }\end{array}$ & $\begin{array}{l}\text { - Liposomal particles can be damaged during } \\
\text { recirculation in pipes and pump. } \\
\text { - Not suitable for low volumes of aqueous phase (at } \\
\text { least } 400 \mathrm{ml} \text { of the aqueous phase is needed for the } \\
\text { circulation in pipes and pumps). }\end{array}$ \\
\hline $\begin{array}{c}\text { Oscillating } \\
\text { membrane } \\
\text { system }\end{array}$ & $\begin{array}{l}\text { - Uniform spatial distribution of shear stress on the } \\
\text { membrane surface. } \\
\text { - } \quad \text { Suitable for fragile and structured particles. } \\
\text { - } \quad \text { Suitable for low volumes of aqueous phase. } \\
\text { - } \quad \text { Suitable for large scale and continuous operation. }\end{array}$ & $\begin{array}{l}\text { - } \quad \text { Complicated and more expensive design. } \\
\text { - } \quad \text { Higher power consumption. } \\
\text { - } \quad \text { Non-uniform temporal distribution of shear stress on } \\
\text { the membrane surface. }\end{array}$ \\
\hline
\end{tabular}




\section{Figure Captions}

Figure 1. Generation of shear stress in membrane microfluidic processes and its spatial or temporal distribution over the membrane surface: (a) Paddle stirrer; (b) continuous phase cross flow; (c) oscillating membrane. All three methods of shear generation were used in this work to enhance the mixing rate of the two phases.

Figure 2. Schematic illustration of the different equipments used in this study: (A) Stirred cell with a simple paddle stirrer above a flat disc membrane $(b=12 \mathrm{~mm}, \mathrm{D}=$ $32 \mathrm{~mm}, \mathrm{D}_{\mathrm{m}}=33 \mathrm{~mm}, \mathrm{n}_{\mathrm{b}}=2$ and $\mathrm{T}=40 \mathrm{~mm}$ ); (B) Cross flow system; (C) Oscillating membrane system.

Figure 3. The variation of the mean vesicle size, $d_{a v}$ and its coefficient of variation, $\mathrm{CV}$ with the final aqueous to organic phase volume ratio: ( $\square$ ) Lipoid E 80, cross flow, $d_{p}=5 \mu \mathrm{m} ;(O)$ POPC, oscillating system, $d_{p}=5 \mu \mathrm{m}$; (ם) Lipoid E 80, cross flow, $d_{p}=$ $20 \mu \mathrm{m} . \tau_{\max }=4.7 \mathrm{~Pa}, \mathrm{~J}=142 \mathrm{I} \mathrm{m}^{-2} \mathrm{~h}^{-1}$. The each data point represents the mean \pm S.D. $(n=3)$.

Figure 4. Transmission electron microscopy of liposomes prepared with (A) stirred cell device (B) cross flow system and (C) oscillating membrane system. 


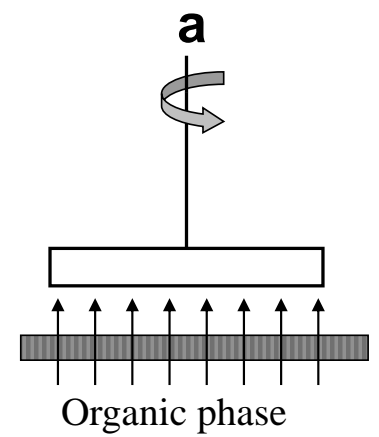

b

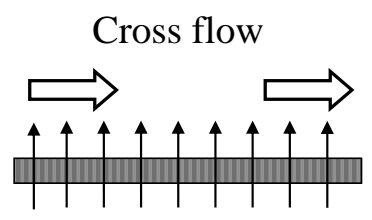

Organic phase
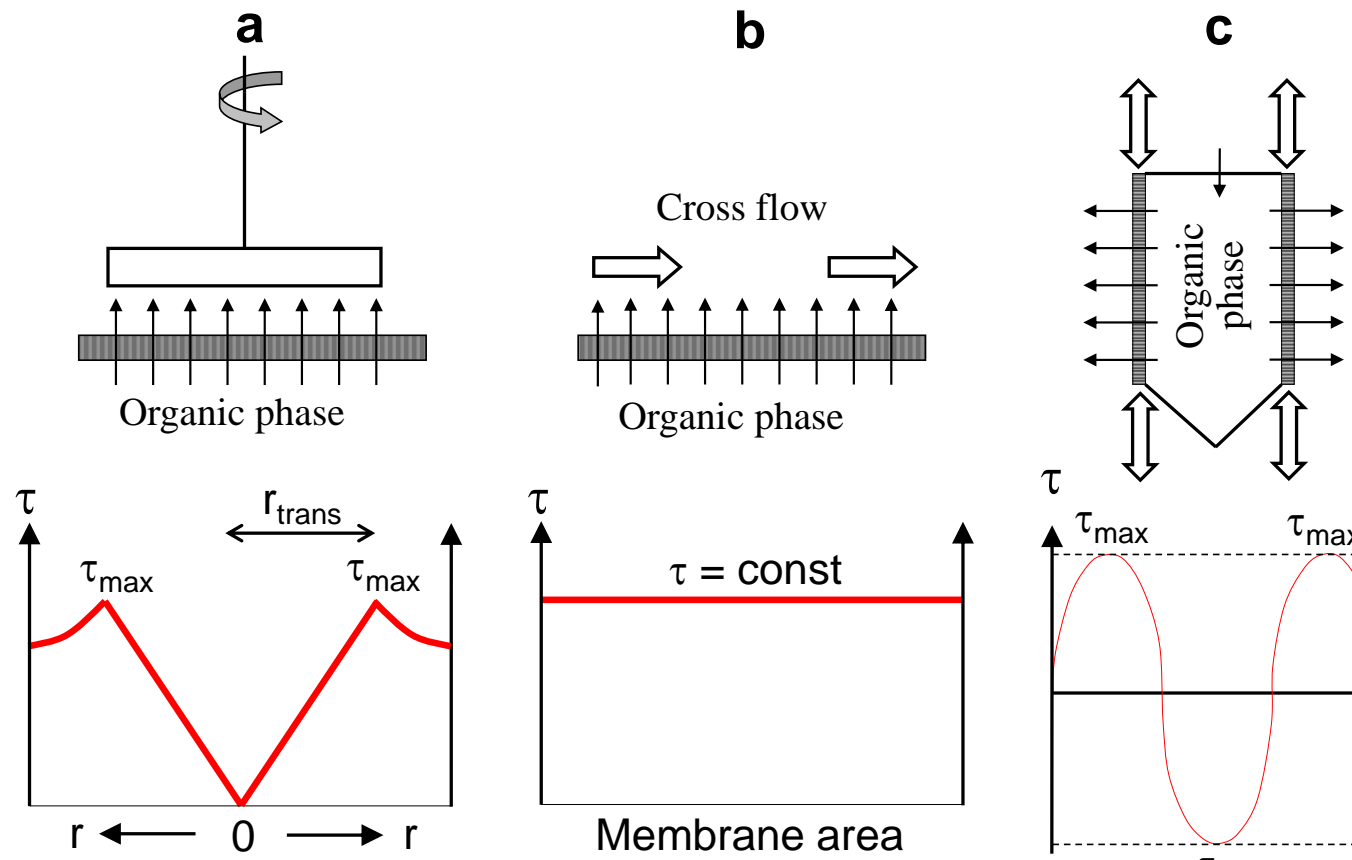

Membrane area

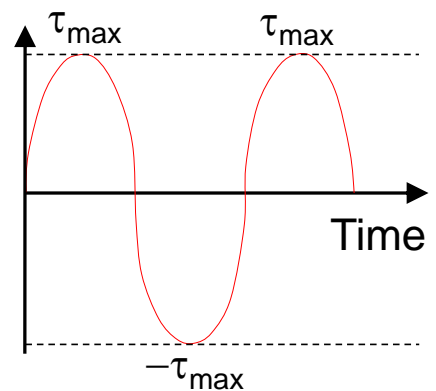


Figure 2

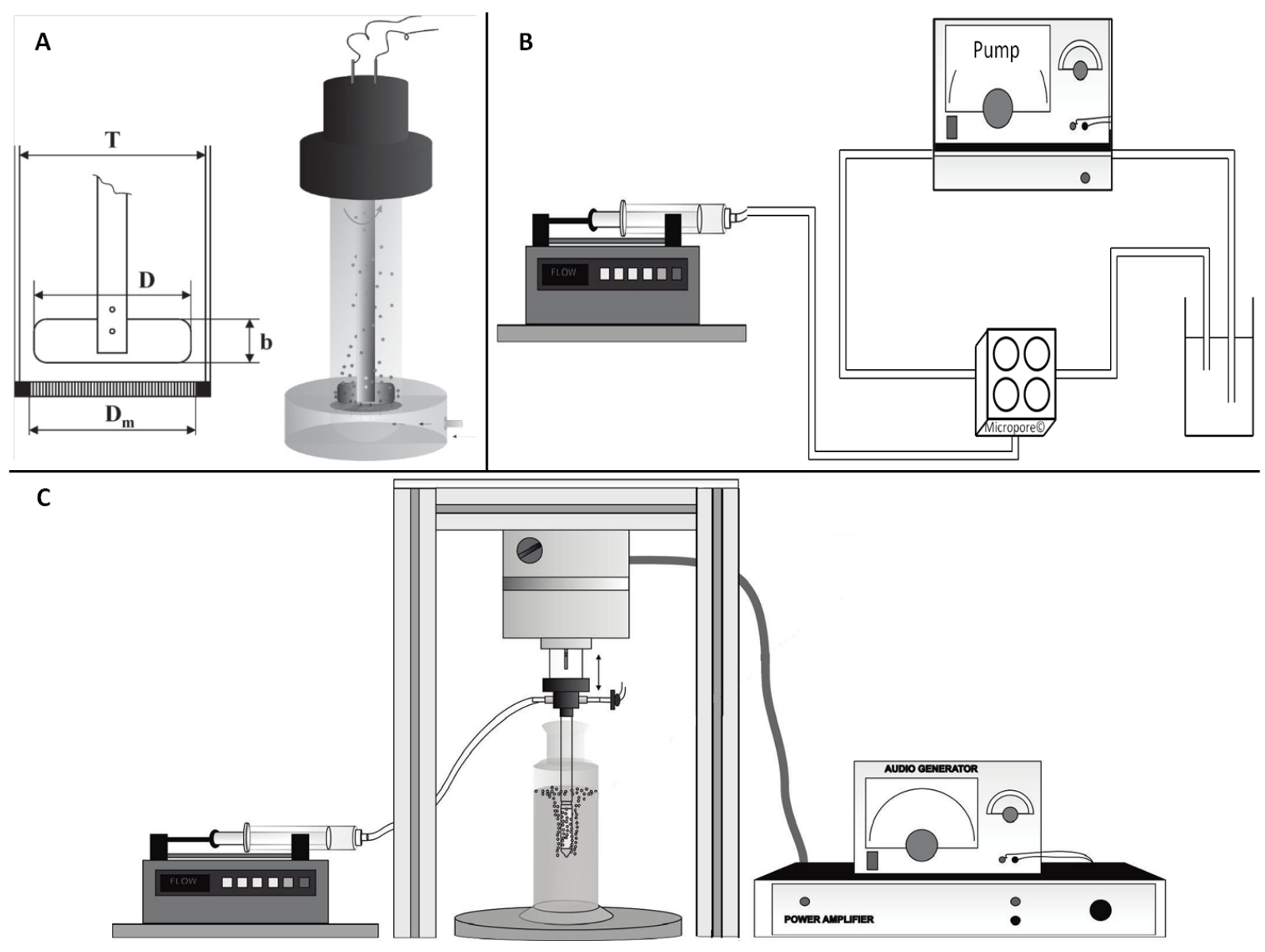



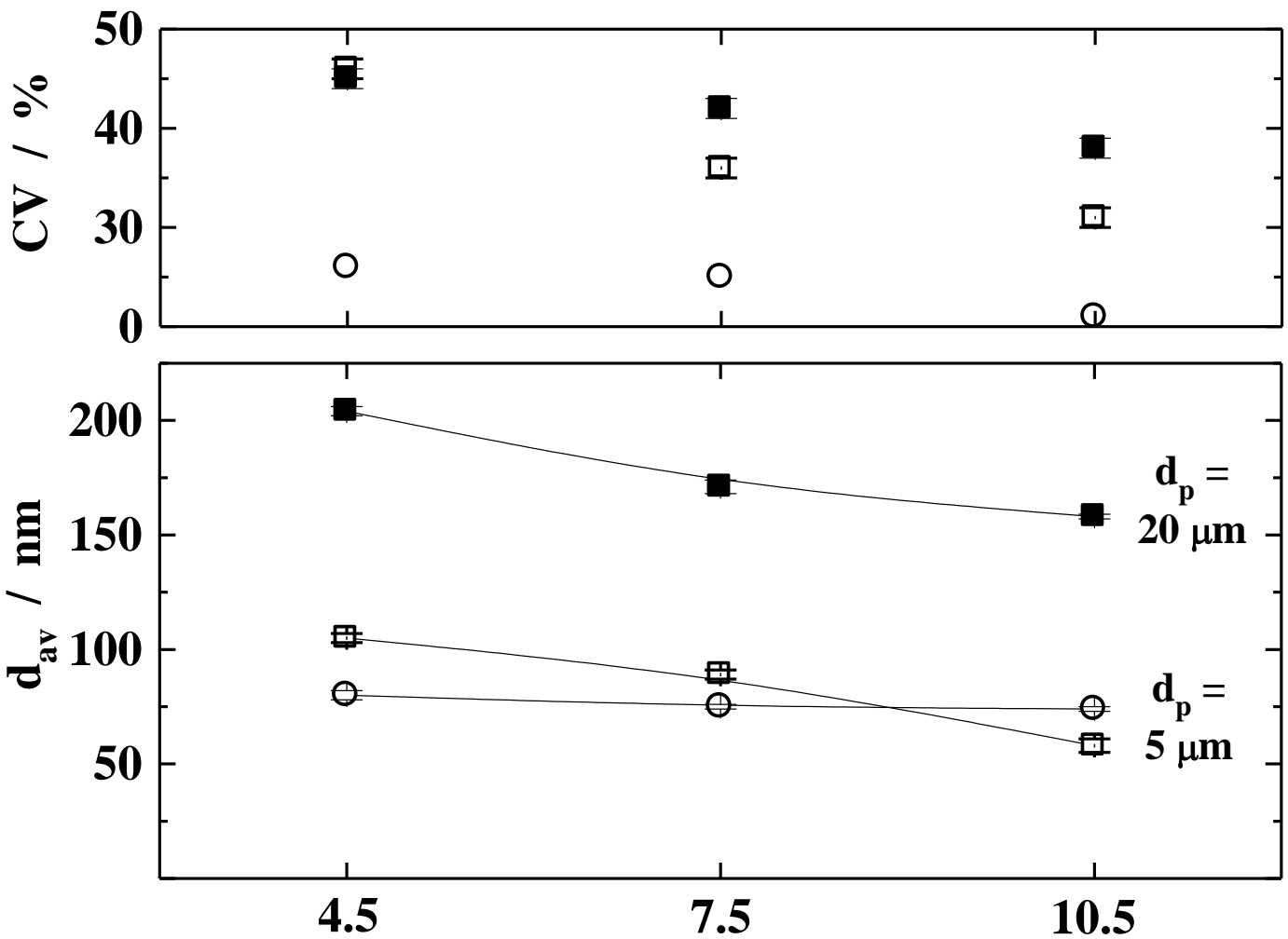

Final aqueous to organic phase volume ratio, $R$ 

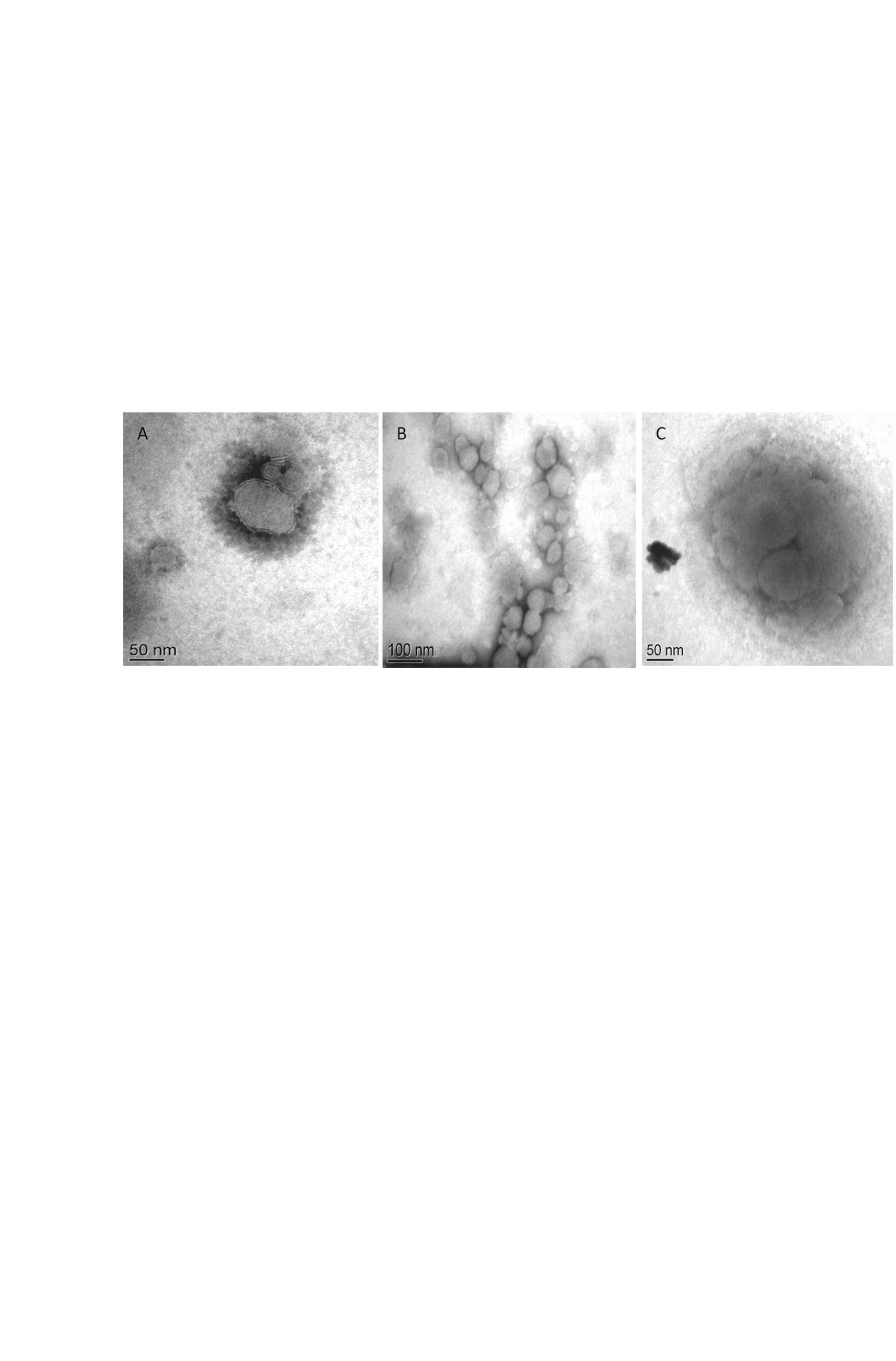

Figure 4

.

\section{Figure 4}

‥

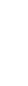

(2)

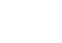

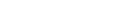

$\sqrt{2}+x^{2}$
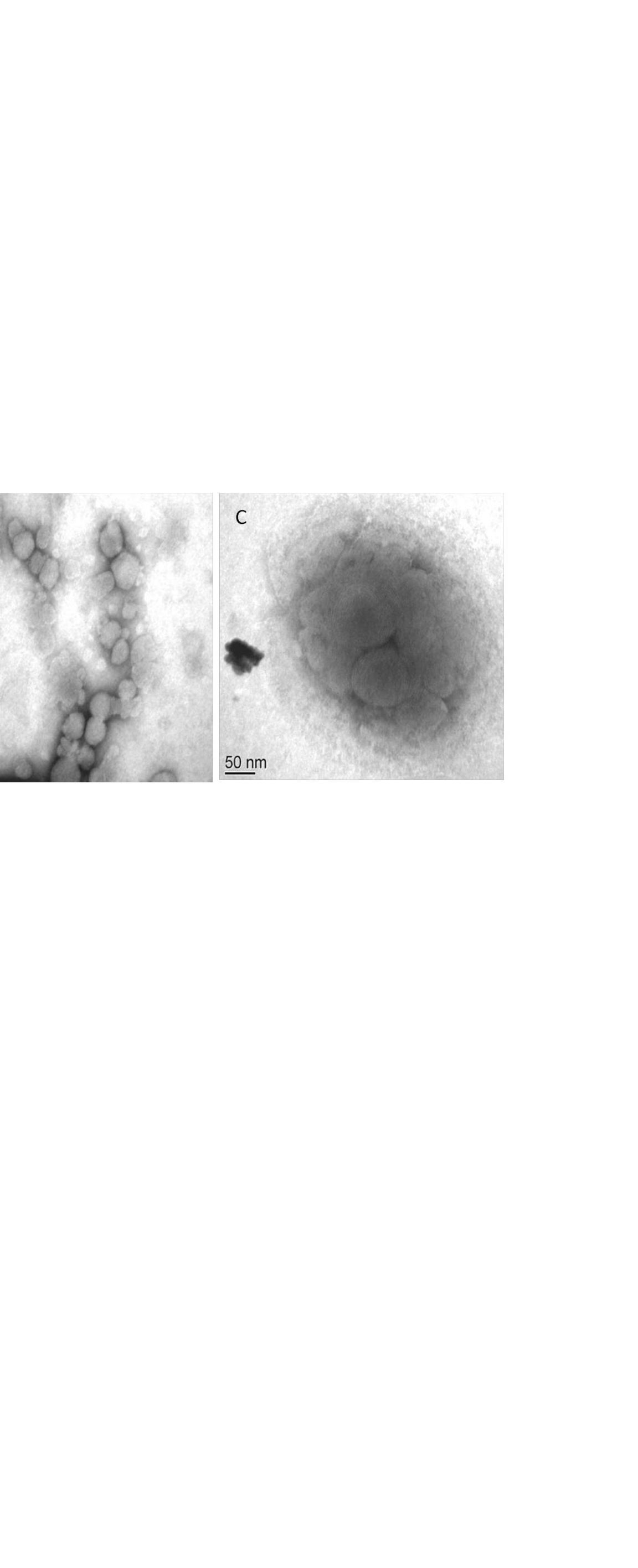